\title{
Asymptotic Approximations to the Isothermal Pyrolysis of Deodara Leaves using Gamma Distribution
}

\section{Edited by \\ Juan Carlos Salcedo-Reyes \\ (salcedo.juan@javeriana.edu.co) \\ 1. Szent Istvan University, Mechanical Engineering PhD School, \\ Faculty of Mechanical Engineering, \\ Godollo, Hungary. \\ 2. Department of Mathematics, Statistics and Computer Science, Govind Ballabh Pant University of \\ Agriculture and Technology, Pantnagar, Uttarakhand, India. \\ *alok.dext@hotmail.com \\ **drsurajbsingh@yahoo.com}

Received: 18-04-2017

Accepted: 26-10-2017

Published on line: 26-12-2017

Citation: Dhaundiyal A, Singh SB. Asymptotic Approximations to the Isothermal Pyrolysis of Deodara Leaves using Gamma Distribution, Universitas Scientiarum, 22 (3): 263-284, 2017. doi: 10.11144/Javeriana.SC22-3.aatt

Funding:

N.A.

Electronic supplementary material: N.A.

OPEN ACCESS

\author{
Alok Dhaundiyal ${ }^{1, *}$, Suraj B. Singh ${ }^{2, * *}$
}

\begin{abstract}
The main aim of this paper pivoted around the influence of some parameters relevant to biomass pyrolysis on the numerical solutions of the $n^{\text {th }}$ order distributed activation energy model (DAEM) using the Gamma distribution. The upper limit of ' $\mathrm{dE}$ ' integral, frequency factor, reaction order, and the shape and rate parameters of the Gamma distribution are investigated. Analysis of the mathematical model is done with the help of asymptotic expansion.
\end{abstract}

Keywords: Asymptotic expansion; Gamma distribution; biomass pyrolysis; distributed activation energy model.

Abbreviations:

$\begin{array}{ll}E_{s} & \text { Central value } \\ E_{w} & \text { Step width } \\ \text { DAEM } & \text { Distributed Activation Energy Model } \\ \text { DExp } & \text { Double Exponential Function }\end{array}$

\section{Introduction}

There are various models which are proposed to describe the pyrolysis of biomass, such as single-reaction and multi-reaction models [1-6]. The most authentic and accurate model considered in this study is the Distributed Activation energy model (DAEM) [7-10]. While the aim of this study is mainly concentrated around the parametric values relevant to the loose biomass, the DAEM also applies to the pyrolysis of other conventional sources including residual oils, resin chars [11], and kerogen [12]. Calculations of the solution to this model may require iterative loops of double integral and rapidly 
varying functions which in turn create significant numerical complications. To tackle this problem, some asymptotic methods have been adopted to make an accurate approximation to the integral and therefore curtail the computation time. Another main source of numerical difficulty is due to the double exponential term $(D E x p)$ in the DAEM, which is investigated for isothermal pyrolysis. The domain of DExp acts over a narrow range of activation energies which changes as time progresses. In this study, the key to our approach is to know the significance of the relative width of the DExp term as compared with the width of the initial distribution.

In this study, the numerical solutions have been obtained by using the asymptotic expansions. The derived results are used to determine the kinetic parameters of the kinetic model. For predicting the realistic results, the parameters affecting the behavior solution must be estimated. The effect of these parameters on the single-reaction model is reviewed in literature [11]. The DAEM is very flexible, and it can successfully describe the pyrolysis of different types of biomass. The main aim of this study is to focus on the relevant parameters which affect the kinetics of pyrolysis. The DAEM is also applicable to the pyrolysis of other conventional sources of energy as Coal, residual oils, resin chars [12], and kerogen [13]. This analytical method is not only used for thermal decomposition of plant or animal biomass $[14,15]$ but also for other materials such as medical wastes [16], waste car tyres [17], printed circuit board wastes [18], or sewage sludge $[19,20]$.

The purview of this paper is to use asymptotic techniques to make an accurate approximation to the double as well as DExp terms and then predict the behavior of the isothermal $n^{\text {th }}$ order DAEM by involving the effect of some relevant parameters on the numerical solution.

\section{Materials and methods}

\section{Distributed Activation Energy Modeling:}

This model includes a reaction time scale, which gained acceptance since it is the significant part of biomass devolatilization [21, 22]. The complication related to DAEM is that the function $f(E)$ and $k_{0}(E)$ are highly correlated, hence it is very difficult to evaluate both the functions accurately. Therefore, it has been assumed that all the frequency factors $k_{0 i}$ to have the same value $k_{0}$, thus it makes analysis easy. The uncertainty of reactant distribution is highly emphasized. The nonisothermal nth DAEM is expressed by equation (1) 


$$
1-X=\left\{\begin{array}{l}
\int_{0}^{\infty} \exp \left[-\int_{0}^{t} k_{0} \exp \left(\frac{-E}{R T}\right) d t\right] f(E) d E \text { (first order reaction) } \\
\int_{0}^{\infty}\left[1-\left(1-n \int_{0}^{t} k_{0} \exp \left(\frac{-E}{R T}\right) d t\right)\right]\left(\frac{1}{1-n}\right) f(E) d E \text { for } n \neq 1
\end{array}\right.
$$

where $X$ is conversion, $n$ is the order of reaction and $f(E)$ is the Gamma distribution function of activation energies.

The value of conversion is found with the help of TGA analysis of cedrus deodara.

$$
X=\frac{m_{o}-m_{t}}{m_{o}-m_{r}}
$$

where, $m_{r}$ is the residual mass, $m_{0}$ is the mass of the sample at beginning of decomposition, and $m_{t}$ is the mass of sample at given time.

Although in most of the study, the symmetrical function is assumed (Gaussian), yet it would be advantageous to choose an asymmetric distribution for modelling the kinetics of biomass pyrolysis, such as the Gamma distribution over a symmetrical one [23]. In addition to that the chosen function is mathematically flexible and can be expressed as:

$$
f(E)=\frac{E^{(\lambda-1)} e^{-\frac{E}{\eta}}}{\eta^{\lambda} \Gamma(\lambda)} \text { for } E>0
$$

where $\lambda$ is the scale parameter expressed in $\mathrm{kJ} / \mathrm{mol}$ and $\eta$ is dimensionless positive shape parameter. The mean and the variance of distribution are given by equation (4) and equation (5) respectively:

$$
\begin{gathered}
E_{0}=\frac{\lambda}{\eta} \\
\sigma^{2}=\frac{\lambda}{\eta^{2}}
\end{gathered}
$$

\section{Approximation methodology}

Equation (1) comprises of two terms. The first term is the DExp which varies with time through temperature history experienced experimentally. The 
second part is the initial distribution function of activation energies that is independent of time. Primarily, the temperature dependant part is considered and thereafter one can derive approximations to solve the DExp.

The isothermal temperature profile only has been involved in this study. In the nonisothermal, linear ramping temperature, the amount of released volatile does not change until the critical time is attained when the two parts of integrand overlap significantly, whereas the variation of volatile release begins to change appreciably at very early times. In case of ramping temperature, the mean value of $D E x p$ changes its location with time in a similar manner to the isothermal temperature case, with logarithmic term replaced by a LambertW function $[24,25]$. However, the step width of DExp, $E_{w}\left(=E_{0} y_{w}\right)$, is narrow at early times, which in turn leads to a major difference in the appearance of the remaining mass fraction curves versus time, between the ramping and constant temperature cases.

Systematic approximations to distributed activation energy model (DAEM)

For approximation of double exponential term, the primal step is to assume the typical values of dependent parameters and rapidly varying functions. The frequency factors $\left(k_{0}\right)$ are in range of $k_{0} \sim 10^{10}-10^{13} \mathrm{~s}^{-1}$, whereas the activation lies in domain of $100-300 \mathrm{~kJ} / \mathrm{mol}$ [24]. The double exponential term is expressed as:

$$
D E x p=\exp \left(-\int_{0}^{t} k_{0} e^{-\frac{E}{R T}} d t\right)
$$

To demonstrate the simplification method, the constant temperature history is assumed to be as follows:

$$
T(l)=T_{o}
$$

Here, $l$ is any instant of time $t$.

After implementing the isothermal condition, DExp becomes

$$
\sim \exp \left(-t k_{0} e^{-\frac{E}{R T_{o}}}\right)
$$

Assume typical values, $\frac{E}{R T_{o}} \sim 10$, while $t k_{0} \sim 10^{10}$. The large size of both these parameters make function, $D E x p$ varies rapidly with $E$. The equation (8) can be further illustrated as: 


$$
\sim \exp \left(\frac{E_{s}-E}{E_{w}}\right)
$$

Where $E_{s} \equiv R T_{0} \ln \left(t k_{0}\right)$ and $E_{w} \equiv R T_{0}$

When the value of $E$ is much less than $E_{s}$, the function approaches zero. Whereas for $E$ much greater than $E_{s}, D E x p$ tends to one. The DExp varies in domain of $[0,1]$ in a range of $E$ with step width of $E_{w}$. The distribution can either be wide or narrow distribution [24]. It depends on the width of DExp as compared to the width of the initial distribution function $f(E)$. In the total integrand of equation (1), DExp is multiplied by the initial distribution function $f(E)$. The shape of the total integrand relies upon the applied limit. When the initial distribution is relatively wide compared to $E_{w}$, the total integrand is initially following the shape of the initial distribution function, but as time proceeds, it is progressively truncated from the left by the step function, DExp. The location of maximum can move significantly and the shape becomes quite skewed. Conversely, the relatively narrow width of initial as compare to DExp makes the shape of the total integrand similar to the initial distribution, with amplitude that is progressively reduced by DExp as time proceeds. The total integrand remains more symmetrical than that of wide distribution. The location of maximum of total integrand does move in the time-dependant manner.

But the scope of this paper is confined itself to the wide distribution case, wherein the width of $f(E)$ is wider than that of $D E x p$.

Using equation (1) and (3), the remaining mass fraction can be expressed as:

$$
1-X=\int_{0}^{\infty} \exp \left(-\exp \left(\frac{E_{s}-E}{E_{w}}\right)\right) \frac{E^{(\lambda-1)} e^{-\frac{E}{\eta}}}{\eta^{\lambda} \Gamma(\lambda)} d E
$$

Let

$$
h(E)=-\exp \left(\frac{E_{s}-E}{E_{w}}\right)-\frac{E}{\eta}
$$

then

$$
1-X=\int_{0}^{\infty} \exp (h(E)) \frac{E^{(\lambda-1)}}{\eta^{\lambda} \Gamma(\lambda)} d E
$$

where $E_{s}$ and $E_{w}$ are functions of $t$ as mentioned earlier. 
Energy is now rescaled as $y=\frac{E}{E_{0}}$, so that the problem becomes

$$
1-X=\frac{\alpha}{\Gamma(\lambda)} \int_{0}^{\infty} y^{(\lambda-1)} \exp (h(y)) d y
$$

let, $\alpha=\frac{\sigma^{2 \lambda}}{E_{o}}$. For the practical purpose $\alpha \ll 1$.

Time is also rescaled as $\tau=k_{0} t$.

For linear ramping temperature $T=\theta t$,

$$
y_{s}=\frac{R T_{0} \ln (\tau)}{E_{0}}, \quad y_{w}=\frac{y_{s}}{\ln (\tau)}
$$

The wide distribution case

It is assumed that the initial distribution is wider than DExp. According to this, $D E x p$ jumps from zero to one near $y=y_{s}$ in such a way that it has been approximated by the step function $[21,22,26,27]$. In order to adopt the wide distribution method, the limit $y_{w} \sqrt[2 \lambda]{\alpha} \ll 1$ is considered. The Heaviside function is written as

$$
H\left(y-y_{s}\right)= \begin{cases}0, & y<y_{s} \\ 1, & y \geq y_{s}\end{cases}
$$

Equation (13) can be written in the form:

$$
\begin{array}{r}
1-X=\frac{\alpha}{\Gamma(\lambda)} \int_{0}^{\infty}\left(\exp \left(-\exp \left(\frac{y_{s}-y}{y_{w}}\right)\right)-H\left(y-y_{s}\right)\right) \\
y^{(\lambda-1)} \exp \left(-(\sigma \sqrt{y})^{2}\right) d y+\frac{\alpha}{\sigma^{2 \lambda} \Gamma(\lambda)} \Gamma\left(\lambda \sigma^{2} y_{s}\right)
\end{array}
$$

where $\Gamma\left(\lambda, \sigma^{2} y_{s}\right)$ is the upper incomplete Gamma function.

The second term in equation (13) is complementary function, and hence easily computed. In fact, in many previous simplification (the step-function approximations) include just this term and neglect the remaining terms. The first integral term is negligibly small everywhere except in a neighbourhood of size $y_{w}$ about the point $y=y_{s}$. Therefore, it can be expanded with the help of Taylor expansion about $y=y_{s}$. 


\section{Suppose}

$$
\begin{aligned}
& S(y)=y^{(\lambda-1)} \exp \left(-(\sigma \sqrt{y})^{2}\right) \\
& S(y) \sim S\left(y_{s}\right)+\left(y-y_{s}\right) S^{\prime}\left(y_{s}\right)+\frac{\left(y-y_{s}\right)^{2}}{2 !} S^{\prime \prime}\left(y_{s}\right)+\frac{\left(y-y_{s}\right)^{3}}{3 !} S^{\prime \prime \prime}\left(y_{s}\right)+\ldots, \\
& S(y) \sim \exp \left(-\left(\sigma \sqrt{y_{s}}\right)^{2}\right)\left[y_{s}^{(\lambda-1)}-\left(y-y_{s}\right) y_{s}{ }^{(\lambda-2)}\left(-\lambda+\sigma^{2} y_{s}+1\right)+\right. \\
& \frac{\left(y-y_{s}\right)^{2}}{2} y_{s}{ }^{(\lambda-3)}\left(\sigma^{4} y_{s}^{2}+2(1-\lambda) \sigma^{2} y_{s}+\left(\lambda^{2}-3 \lambda+2\right)\right)- \\
& \frac{\left(y-y_{s}\right)^{3}}{6} y_{s}^{(\lambda-4)}\left(\sigma^{6} y_{s}{ }^{3}+3(1-\lambda) \sigma^{4} y_{s}^{2}+\right. \\
& \left.\left.\left(3 \lambda^{2}-9 \lambda+6\right) \sigma^{2} y_{s}-\lambda^{3}+6 \lambda^{2}-11 \lambda+6\right)\right]
\end{aligned}
$$

Putting $\frac{y-y_{s}}{y_{w}}=x, d y=y_{w} d x$ in equation (17), we have

$$
\begin{array}{r}
S(y) \sim \exp \left(-\left(\sigma \sqrt{y_{s}}\right)^{2}\right)\left[y_{s}{ }^{(\lambda-1)}-y_{w} x y_{s}^{(\lambda-2)}\left(-\lambda+\sigma^{2} y_{s}+1\right)+\right. \\
\frac{\left(y_{w} x\right)^{2}}{2} y_{s}{ }^{(\lambda-3)}\left(\sigma^{4} y_{s}{ }^{2}+2(1-\lambda) \sigma^{2} y_{s}+\left(\lambda^{2}-3 \lambda+2\right)\right)- \\
\frac{\left(y_{w} x\right)^{3}}{6} y_{s}{ }^{(\lambda-4)}\left(\sigma^{6} y_{s}{ }^{3}+3(1-\lambda) \sigma^{4} y_{s}{ }^{2}+\right. \\
\left.\left.\left(3 \lambda^{2}-9 \lambda+6\right) \sigma^{2} y_{s}-\lambda^{3}+6 \lambda^{2}-11 \lambda+6\right)\right]
\end{array}
$$


From equations (17) and (18), we have

$$
\begin{aligned}
& 1-X=\frac{\alpha}{\sigma^{2 \lambda} \Gamma(\lambda)} \Gamma\left(\lambda, \sigma^{2} y_{s}\right)+ \\
& \frac{\alpha}{\Gamma(\lambda)} \int_{0}^{\infty}(\exp (-\exp (-x))-H(x)) \exp \left(-\left(\sigma \sqrt{y_{s}}\right)^{2}\right) \\
& {\left[y_{s}{ }^{(\lambda-1)}-y_{w} x y_{s}^{(\lambda-2)}\left(-\lambda+\sigma^{2} y_{s}+1\right)+\right.} \\
& \frac{\left(y_{w} x\right)^{2}}{2} y_{s}{ }^{(\lambda-3)}\left(\sigma^{4} y_{s}^{2}+2(1-\lambda) \sigma^{2} y_{s}+\right. \\
& \left.\left(\lambda^{2}-3 \lambda+2\right)\right)-\frac{\left(y_{w} x\right)^{3}}{6} y_{s}^{(\lambda-4)}\left(\sigma^{6} y_{s}^{3}+3(1-\lambda) \sigma^{4} y_{s}^{2}+\right. \\
& \left.\left.\left(3 \lambda^{2}-9 \lambda+6\right) \sigma^{2} y_{s}-\lambda^{3}+6 \lambda^{2}-11 \lambda+6\right)\right] y_{w} d x
\end{aligned}
$$

or

$$
\begin{aligned}
& 1-X \sim \frac{\alpha}{\sigma^{2 \lambda} \Gamma(\lambda)} \Gamma\left(\lambda, \sigma^{2} y_{s}\right)+\frac{\alpha}{\Gamma(\lambda)} \exp \left(-\left(\sigma \sqrt{y_{s}}\right)^{2}\right) y_{s}^{(\lambda-1)} y_{w} \\
& {\left[L_{0}-\frac{y_{w}}{y_{s}} L_{1}\left(-\lambda+\sigma^{2} y_{s}+1\right)+\frac{1}{2}\left(\frac{y_{w}}{y_{s}}\right)^{2} L_{2}\left(\sigma^{4} y_{s}^{2}+2(1-\lambda) \sigma^{2} y_{s}+\right.\right.} \\
& \left.\left(\lambda^{2}-3 \lambda+2\right)\right)-\frac{1}{6}\left(\frac{y_{W}}{y_{s}}\right)^{3} L_{3}\left(\sigma^{6} y_{s}^{3}+3(1-\lambda) \sigma^{4} y_{s}^{2}+\right. \\
& \left.\left.\left(3 \lambda^{2}-9 \lambda+6\right) \sigma^{2} y_{s}-\lambda^{3}+6 \lambda^{2}-11 \lambda+6\right)\right]
\end{aligned}
$$


We know that

$$
\frac{\Gamma\left(\lambda, \sigma^{2} y_{S}\right)}{\Gamma(\lambda)}=1-P\left(\lambda, \sigma^{2} y_{s}\right)
$$

where $P\left(\lambda, \sigma^{2} y_{S}\right)=\frac{\gamma\left(\lambda, \sigma^{2} y_{S}\right)}{\Gamma(\lambda)}$ is the lower cumulative distribution.

Coefficient $L_{i}$ is independent of any parameters and the some few values are evaluated as:

$L_{0} \approx-0.5772, L_{1} \approx-0.98906, L_{2} \approx-1.81496, L_{3} \approx-5.89037$

The remaining integral terms are estimated by the expression

$$
L_{n} \equiv \int_{-\infty}^{\infty} x^{n}\left(e^{-e^{-x}}-H(x)\right) d x
$$

The equation (20) is the required expression for the first order reaction.

In the same manner, the approximations can be obtained for $n^{\text {th }}$ order reactions by invoking equation (1).

The equation (1) for nth order reactions is written as:

$$
\begin{aligned}
& (1-X) n^{t h} \sim \int_{0}^{\infty}\left[1-\exp \left(\frac{y_{s}-y}{y_{w}}\right)+\frac{n}{2} \exp \left(2\left(\frac{y_{s}-y}{y_{w}}\right)\right)\right. \\
& \left.-\frac{(2 n-1)}{6} \exp \left(3\left(\frac{y_{s}-y}{y_{w}}\right)\right)+\cdots\right] \frac{\alpha y^{(\lambda-1)} \exp \left(-(\sigma \sqrt{y})^{2}\right.}{\Gamma(\lambda)} d y
\end{aligned}
$$


Using the wide distribution limit, the equation (23) can be expressed as:

$$
\begin{aligned}
& (1-X) n^{t h} \sim \int_{0}^{\infty}\left[1-\left(\exp \left(\frac{y_{s}-y}{y_{w}}\right)-H\left(y_{s}-y\right)\right)+\right. \\
& \frac{n}{2}\left(\exp \left(2\left(\frac{y_{s}-y}{y_{w}}\right)\right)-H\left(y_{S}-y\right)\right)- \\
& \left.\frac{(2 n-1)}{6}\left(\exp \left(3\left(\frac{y_{s}-y}{y_{w}}\right)\right)-H\left(y_{s}-y\right)\right)+\cdots\right] \\
& \frac{\alpha y^{(\lambda-1)} \exp \left(-(\sigma \sqrt{y})^{2}\right.}{\Gamma(\lambda)} d y
\end{aligned}
$$

or

$$
\begin{aligned}
& (1-X) n^{t h} \sim \frac{\alpha}{\sigma^{2 \lambda}}\left(1+\frac{(n-5)}{6} \frac{\Gamma\left(\lambda, \sigma^{2} y_{s}\right)}{\Gamma(\lambda)}\right)+ \\
& \frac{\alpha}{\Gamma(\lambda)} \exp \left(-\left(\sigma{\sqrt{y_{s}}}^{2}\right) y_{s}^{(\lambda-1)} y_{w}\left(\left[\left(p_{o}+\frac{n}{2} M_{0}-\frac{(2 n-1)}{6} N_{0}\right)-\right.\right.\right. \\
& \frac{y_{W}}{y_{s}}\left(p_{1}+\frac{n}{2} M_{0}-\frac{(2 n-1)}{6} N_{1}\right)\left(-\lambda+\sigma^{2} y_{s}+1\right)+ \\
& \frac{1}{2}\left(\frac{y_{w}}{y_{S}}\right)^{2}\left(p_{2}+\frac{n}{2} M_{2}-\frac{(2 n-1)}{6} N_{2}\right)\left(\sigma^{4} y_{s}^{2}+2(1-\lambda) \sigma^{2} y_{s}+\left(\lambda^{2}-3 \lambda+2\right)\right)- \\
& \frac{1}{6}\left(\frac{y_{w}}{y_{s}}\right)^{3}\left(p_{3}+\frac{n}{2} M_{3}-\frac{(2 n-1)}{6} N_{3}\right) \\
& \left.\left.\left(\sigma^{6} y_{s}^{3}+3(1-\lambda) \sigma^{4} y_{s}^{2}+\left(3 \lambda^{2}-9 \lambda+6\right) \sigma^{2} y_{s}-\lambda^{3}+6 \lambda^{2}-11 \lambda+6\right)\right]\right)
\end{aligned}
$$


The coefficients $P_{n}, M_{n}$ and $N_{n}$ values are evaluated as:

$$
\begin{aligned}
& P_{0} \approx-0.36788, \quad P_{1} \approx-0.23576, \quad P_{2} \approx-0.17273, \quad P_{3} \approx-0.13607 \\
& M_{0} \approx-0.56767, \quad M_{1} \approx-0.35150, \quad M_{2} \approx-0.25250, \quad M_{3} \approx-0.19642 \\
& N_{0} \approx-0.68326, \quad N_{1} \approx-0.41102, \quad N_{2} \approx-0.29061, \quad N_{3} \approx-0.22387
\end{aligned}
$$

The other integral terms can be evaluated as:

$$
\begin{gathered}
P_{n} \equiv \int_{-\infty}^{\infty} x^{i}(\exp (-x)-U(x)) d x, i=0,1,2,3 \ldots \\
M_{n} \equiv \int_{-\infty}^{\infty} x^{i}(\exp (-2 x)-U(x)) d x, i=0,1,2,3 \ldots . \\
N_{n} \equiv \int_{-\infty}^{\infty} x^{i}(\exp (-3 x)-U(x)) d x, i=0,1,2,3 \ldots .
\end{gathered}
$$

Application of loose biomass and computation methodology

The sample of Cedrus deodar underwent isothermal pyrolysis. Elemental composition is evaluated with the help of CHNS $(\mathrm{O})$ analyser (Flash-EA 1112 series). TGA/DTA (Exstar 6300) analysis has been performed in the presence of inert atmosphere of Nitrogen. An alumina crucible is used to hold the sample. The purge flow rate is fixed to be $200 \mathrm{~mL} / \mathrm{min}$. Dulong's formula for estimating the calorific value of a solid fuel is used to evaluate the high calorific value of sample [28]. Thermocouple ' $R$ ' type is used to measure the furnace temperature.

It is to be noted that the results of this analysis are used for the prediction of nth order DAEM using the Gamma distribution. Computation of equations (20) and (25) are done with the help of MATLAB algorithm. Accurately approximated results are obtained by minimizing the root mean square error between experimental and predicted value. Iterative loops are used for lengthy computation of DAEM equations. Fig. 6. demonstrates that the $n^{\text {th }}$ order Gamma DAEM provides the good fit with experimental data. 
Table 1. Chemical composition of Cedrus deodara leaves *- Higher heating value.

\begin{tabular}{cccccc}
\hline $\mathbf{C} \%$ & $\mathbf{H} \%$ & $\mathbf{N} \%$ & $\mathbf{O} \%$ & $\mathbf{S} \%$ & HHV* $(\mathbf{M J} / \mathbf{k g})$ \\
\hline 47.68 & 7.6765 & 2.0285 & 32.511 & 0.000 & 21.318 \\
\hline
\end{tabular}

\section{Result and discussions}

The numerical solution of equation (1) is carried out with the help of asymptotic expansion. The parametric influence of upper limit $\left(E_{\infty}\right)$ is illustrated in Fig. 1. At the initial stage of the pyrolysis, the remaining mass proportion $(1-X)$ must be close to one. While it has been observed in Figure 1 that the remaining mass fraction is less than one for $E_{\infty}<8.33 \mathrm{kJmol}^{-1}$ values. When more than $11.33 \mathrm{~kJ}$ is applied, the results are more accurate and closely overlapped with each other. Therefore, $13.8 \mathrm{~kJ} \mathrm{~mol}^{-1}$ can be adopted as an upper limit of the ' $\mathrm{dE}$ ' integral. The behaviour of $(1-X)$ curves with variation of frequency factor $(A)$ on the numerical results is depicted in Fig. 2. According to these curves, increment in A shifts the curves to the left direction.

The effect of scale parameters on the numerical solution is shown in Fig. 3. Where it is visible that the remaining mass proportion curves shifted up for the lower value of scale parameter $(\lambda)$. Therefore, the initial value of $(1-X)$ becomes more than one, which provides inaccuracy of the predictive algorithm for the values of $\lambda$ less than equal to $35.85 \mathrm{~kJ}$ mol-1. The effect of shape parameter $(\eta)$ on the numerical solution is depicted in Fig. 4. For the values of $\eta$ less than 13.36 , the remaining mass curves shifted down and become constant with time.

Thus, it is concluded that the converse rate of biomass becomes constant and hence, the remaining mass fraction curves show the asymptotic behavior with time as the shape parameter decreases. The effect of the reaction order $(n)$ values on the numerical results is illustrated in Fig. 5. from which it is seen that increase in reaction order $(n)$ causes $(1-X)$ curves to shift up. 
a)

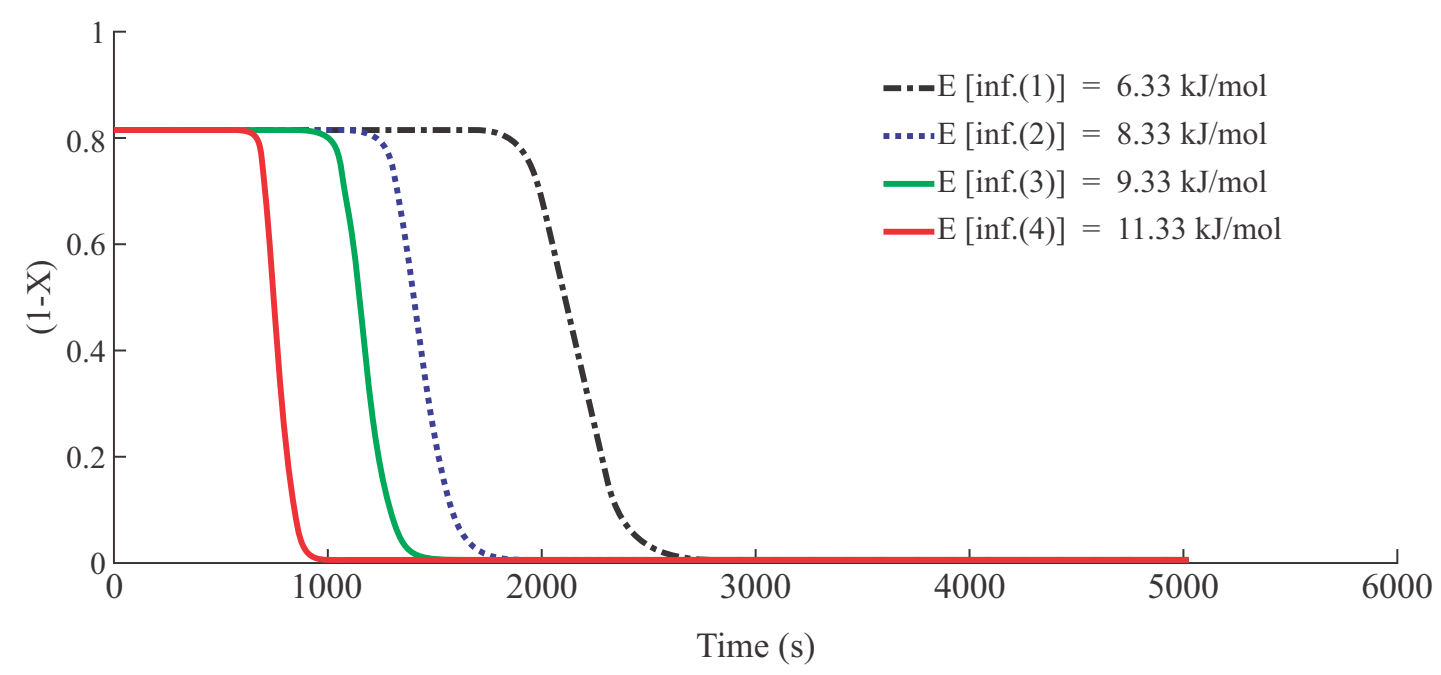

b)

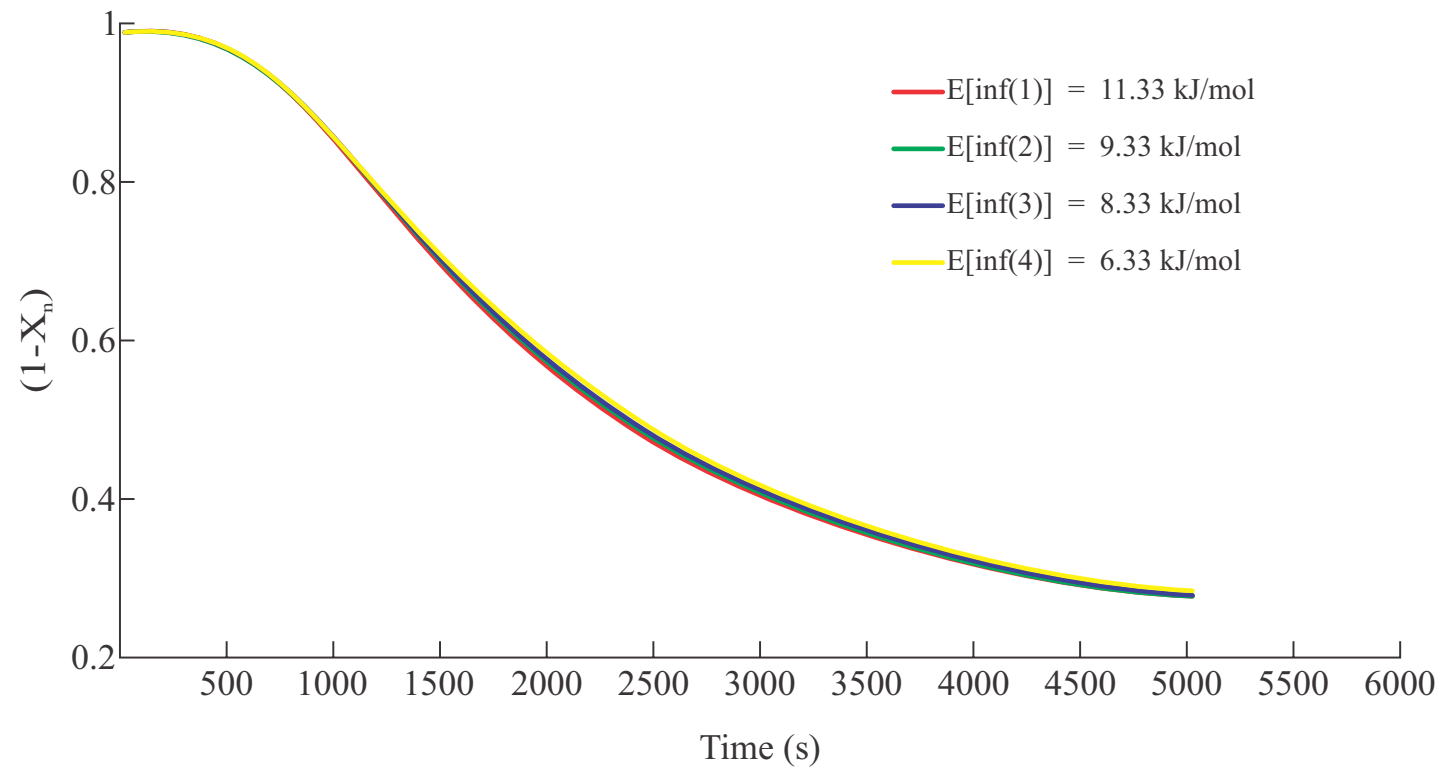

Figure 1. The effect of upper limit $\left(E_{\infty}\right)$ of ' $\mathrm{E}$ ' integral on the numerical solution ( $T_{0}=564 \mathrm{~K}, A=1.2 \mathrm{~ms}^{-1}, \eta=23.87, \lambda=130 \mathrm{kJmol}^{-1}$ and $\left.n=11\right)$ (a. first order reaction, b. $n^{\text {th }}$ order reaction).

Unlike Gaussian [29], Weibull [30] and Rayleigh [31] distribution functions, Gamma distribution relatively converges at very low value of activation energies. It also implies that sensitivity of Gamma distribution while modeling the biomass pyrolysis is quite high. The sudden variation in relevant parameters of biomass pyrolysis led to the drastic variation in the curvature of the remaining mass fraction. Therefore, the variation of activation energies in between different reactions is negligibly small. 


\section{a)}

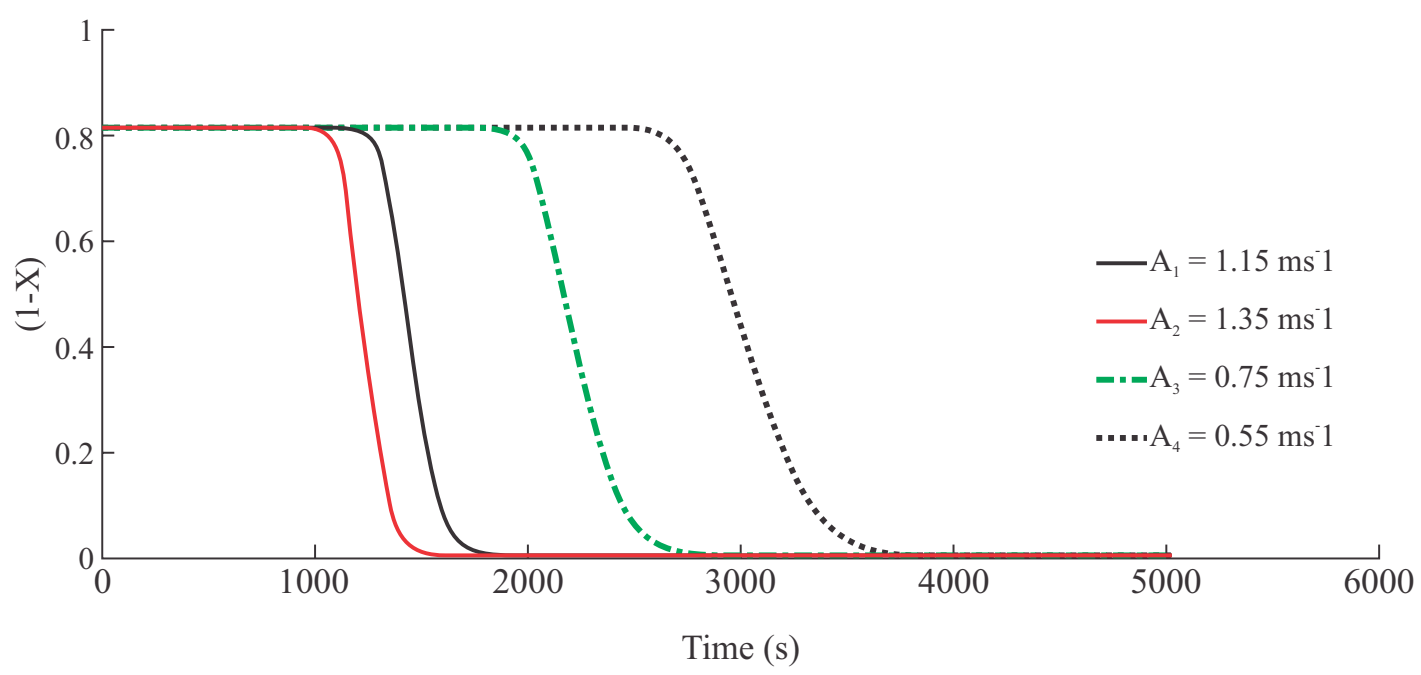

b)

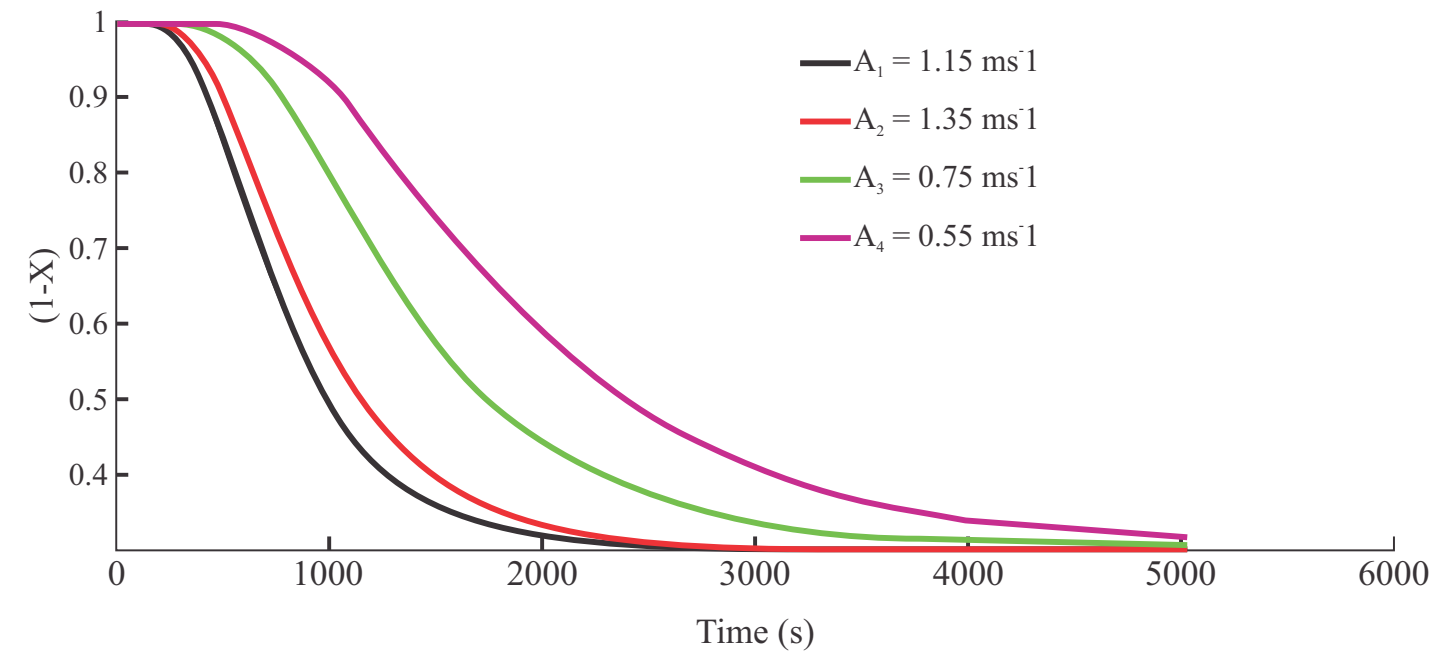

Figure 2. The effect of frequency factors $(A)$ on the numerical solution $\left(T_{0}=564 \mathrm{~K}, E_{\infty}=7.33 \mathrm{kJmol}^{-1}, \eta=23.87, \lambda=130 \mathrm{kJmol}^{-1}\right.$ and $\left.n=11\right)$ (a. first order reaction, b. $n^{\text {th }}$ order reaction). 
a)

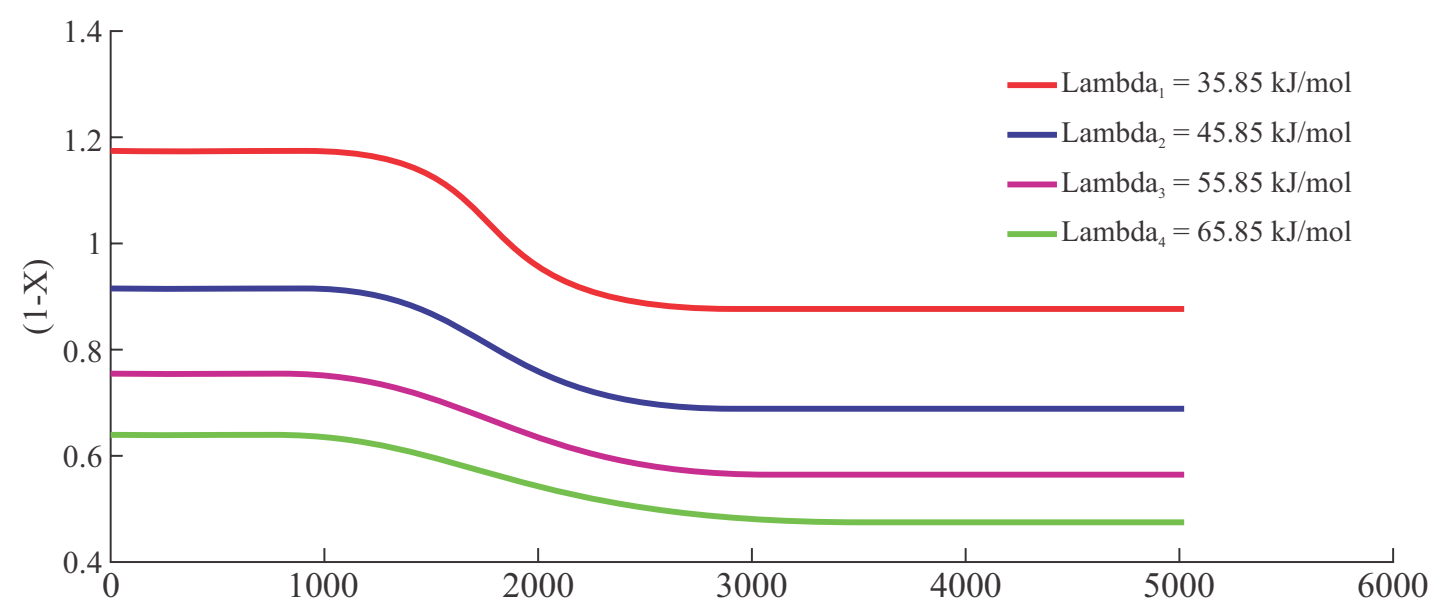

Time (s)

b)

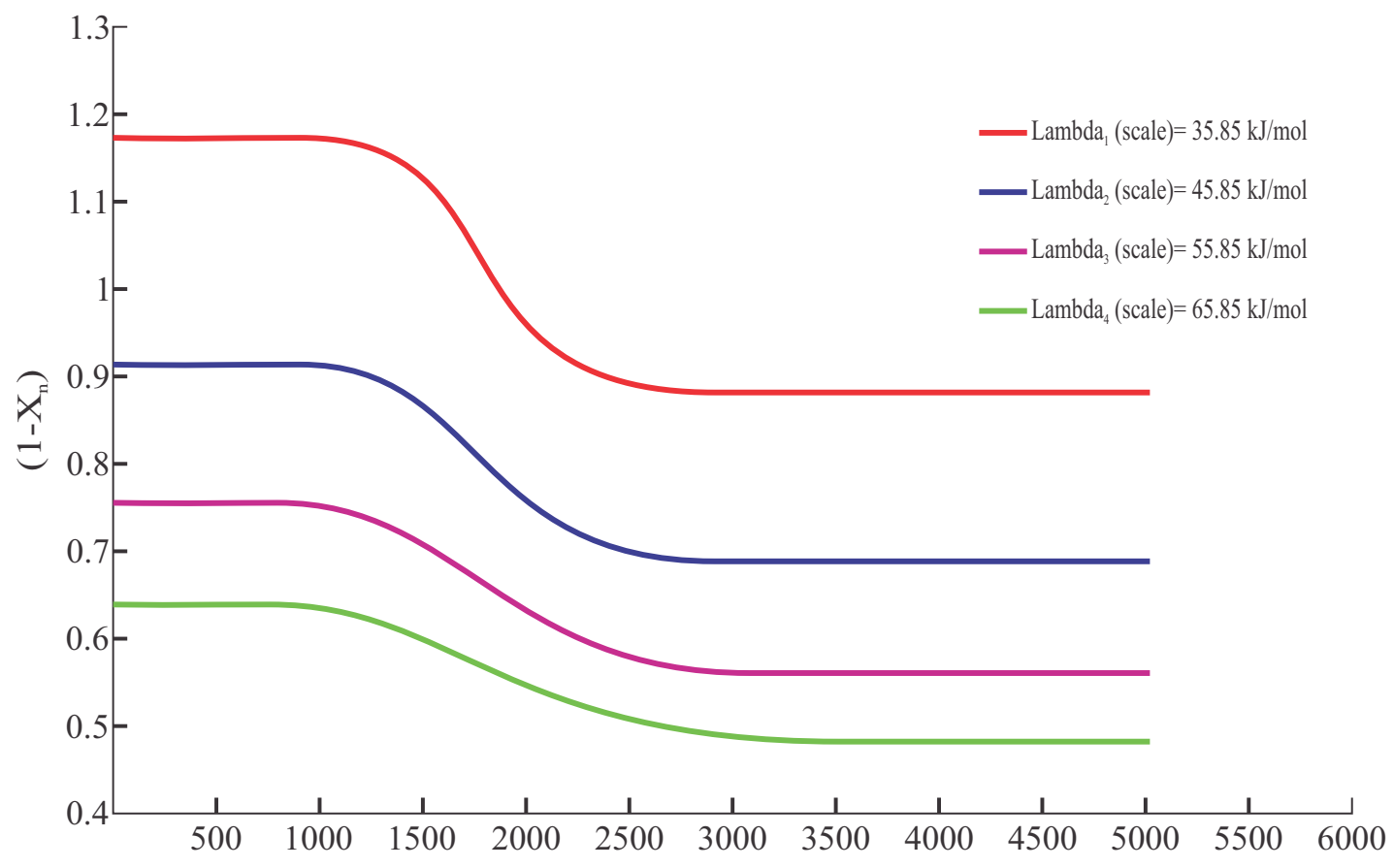

Time (s)

Figure 3. The effect of scale parameter $(\lambda)$ of the Gamma distribution on the numerical solution $\left(T_{0}=564 K, E_{\infty}=7.33 \mathrm{kJmol}^{-1}, \eta=23.87\right.$ and $\left.n=11\right)$ (a. first order reaction, b. $n^{\text {th }}$ order reaction). 
a)

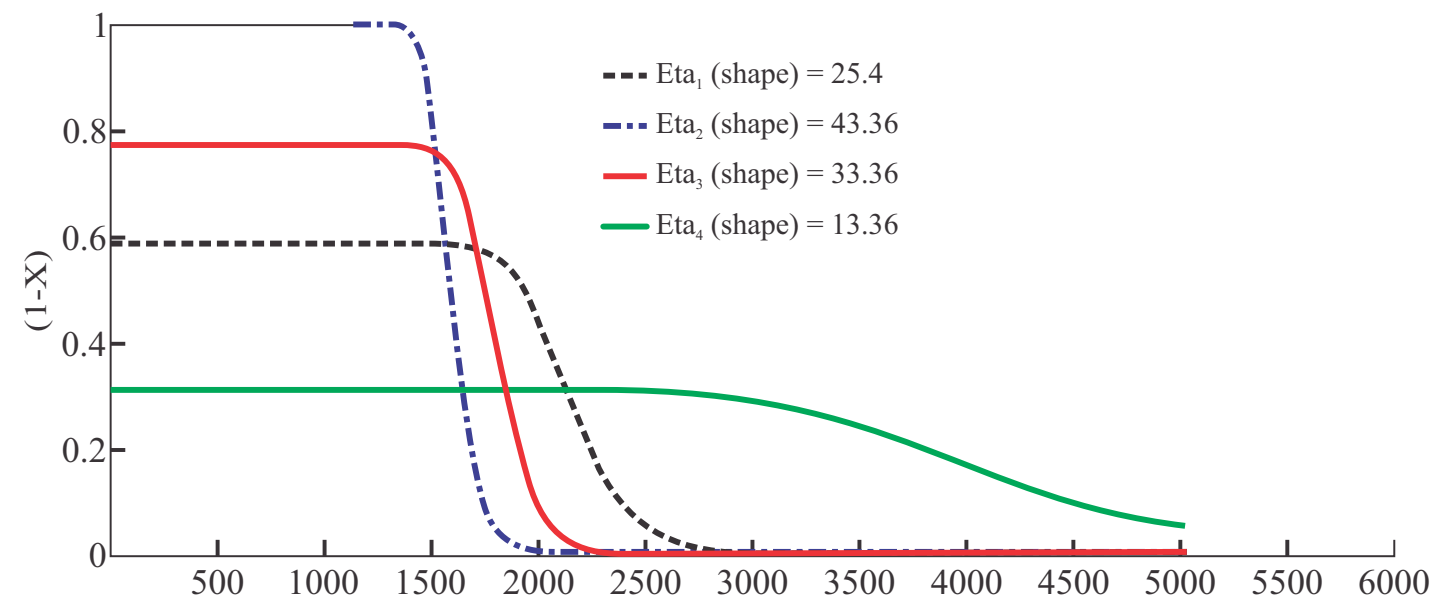

Time (s)

b)

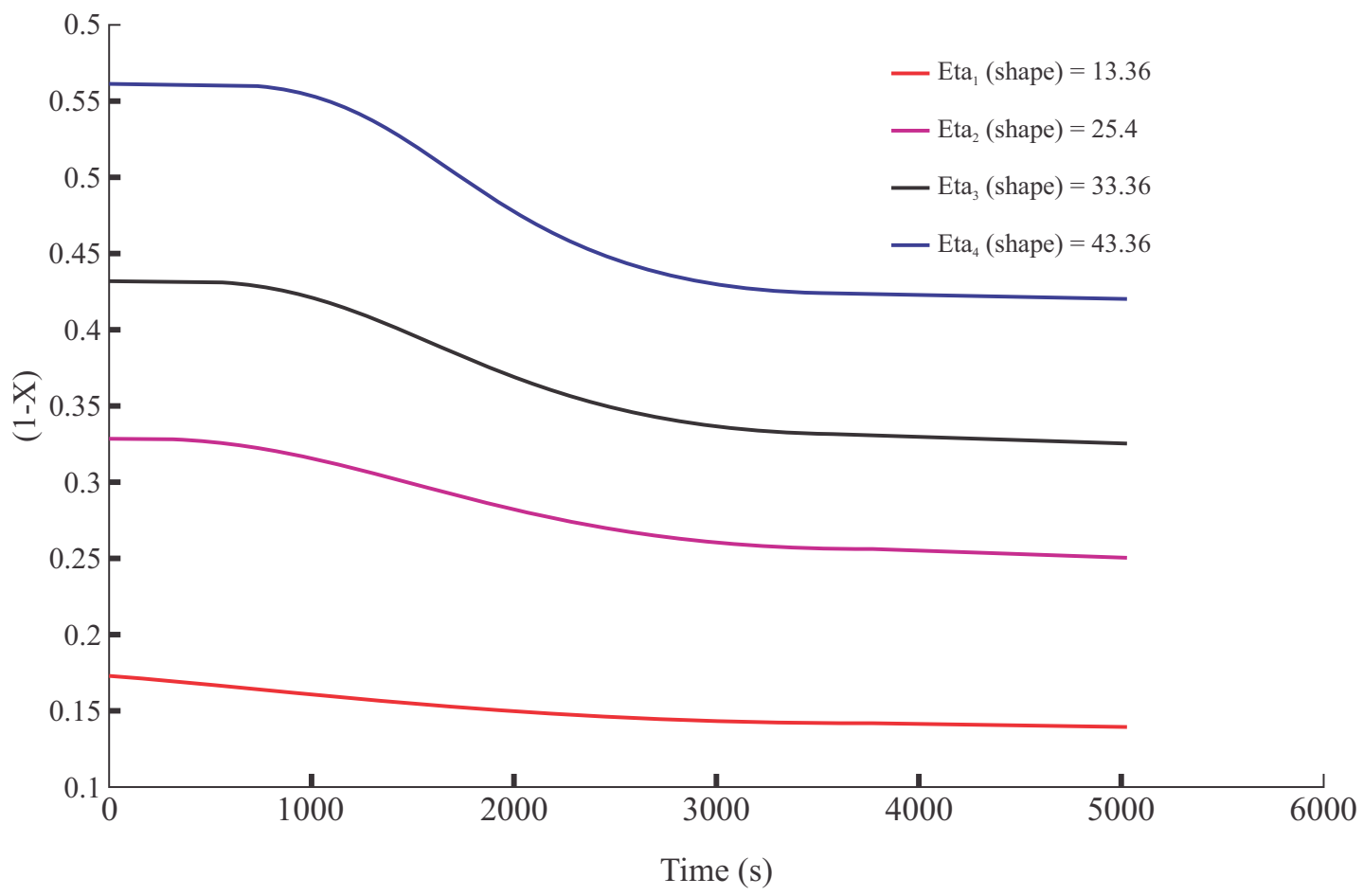

Figure 4. The effect of shape parameter $(\eta)$ of 'dE' integral on the numerical solution $\left(T_{0}=564 K, A=1.2 \mathrm{~ms}^{-1}, \lambda=130 \mathrm{kJmol}^{-1}, E_{\infty}=7.33 \mathrm{kJmol}^{-1}\right.$ and $n=11$ ) (a. first order reaction, b. $n^{\text {th }}$ order reaction). 


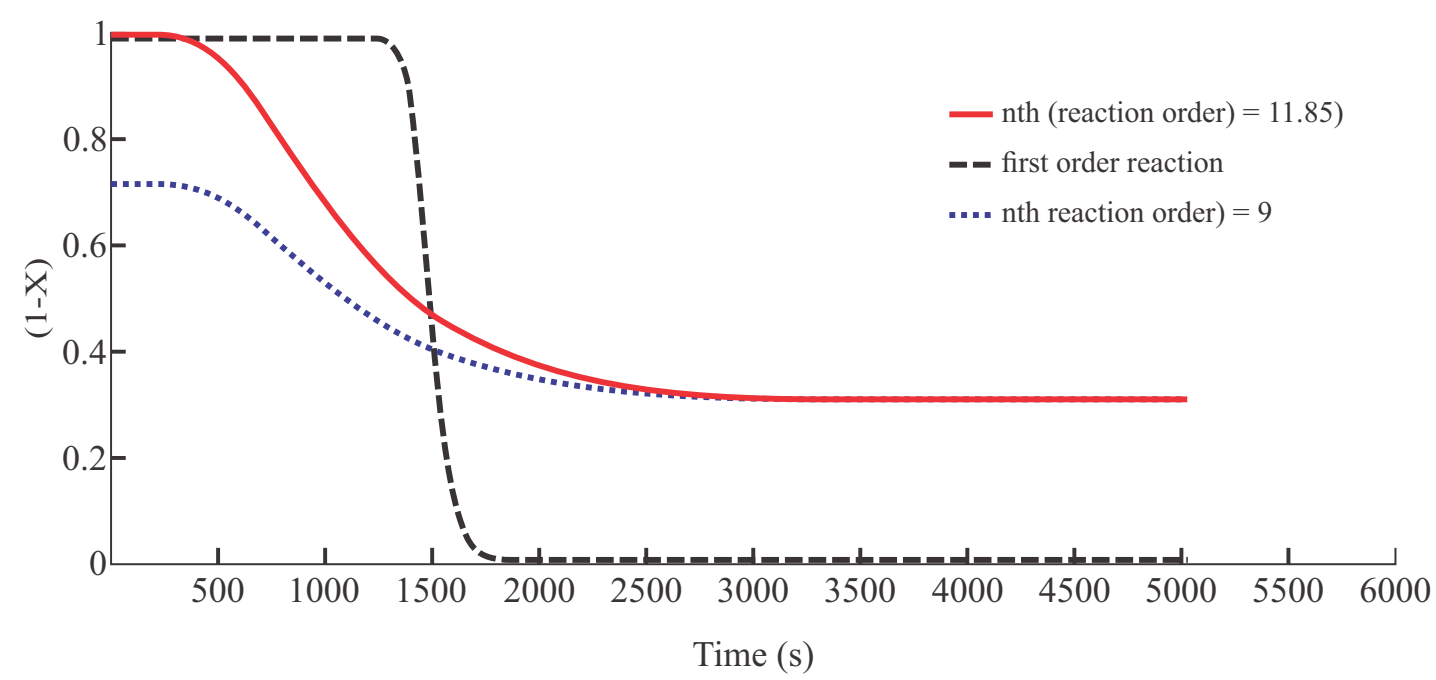

Figure 5. The effect of reaction order $(n)$ on the numerical solution $\left(T_{0}=564 K, A=1.2 \mathrm{~ms}^{-1}, \eta=23.87, \lambda=130 \mathrm{kJmol}^{-1}\right)$.

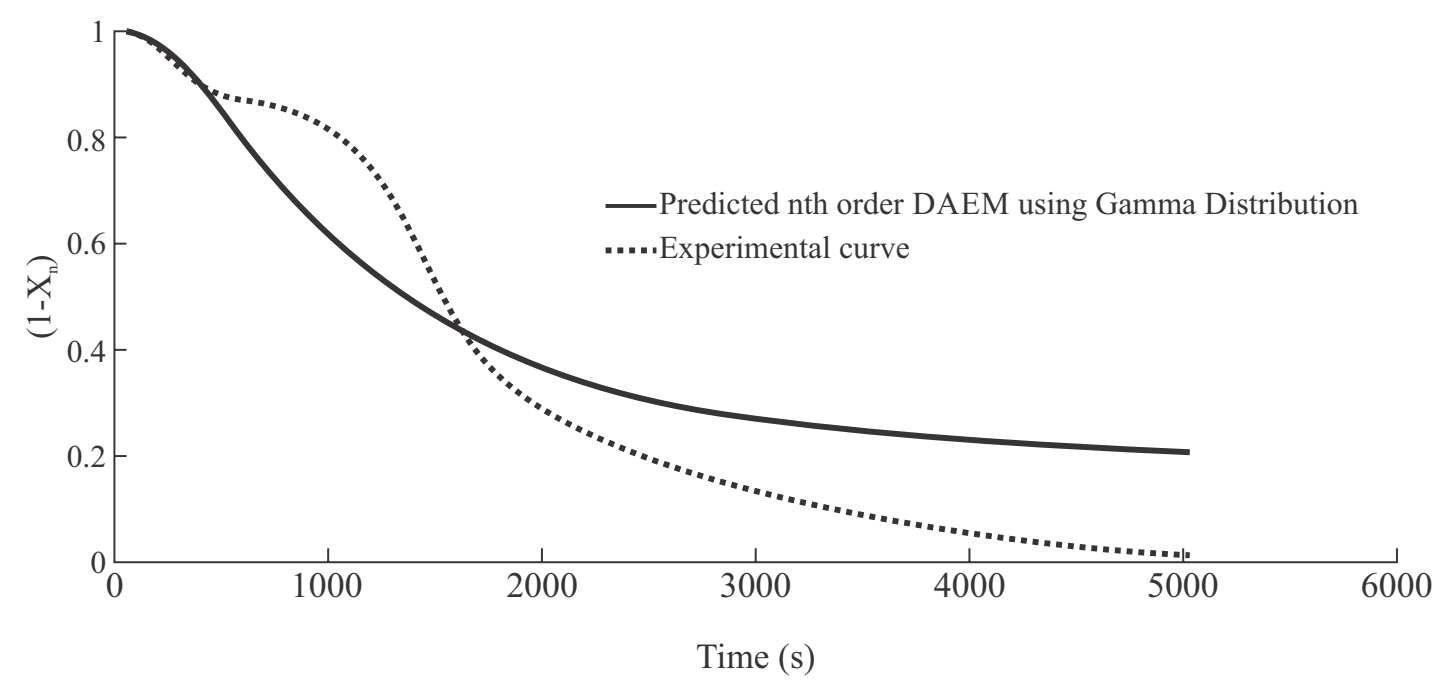

Figure 6. Comparison of thermoanalytical data with the predicted $n^{\text {th }}$ order isothermal DAEM using the Gamma distribution.

\section{Conclusions}

Numerical solution of Gamma distribution is derived by using asymptotic approximations to double exponential term. It has been found that the upper limit of ' $\mathrm{dE}$ ' provided a good curve fitting at $13.8 \mathrm{kJmol}^{-1}$; whereas the 
remaining mass fraction curves did not predict an accurate result for all the value of $E_{\infty} \leq 11 \mathrm{kJmol}^{-1}$. Furthermore, the effect of frequency factor, reaction order, and shape and scale parameters of Gamma distribution merely influenced attribute of $(1-X)$ curves. However, the remaining mass fraction curves did not simulate the mechanism of the reaction occurring at the high-temperature regime. If we replace the initial distribution function from some other multivariate function which bifurcates the behavior of biomass pyrolysis at lower as well as higher temperature regimes, it may provide a much more promising outcome than that of univariant function.

\section{Competing interests}

The authors hereby pronounce no competing interests.

\section{Acknowledgments}

Authors wish to expresses their gratitude to IIC, IIT Roorkee and SAIF, IIT Bombay for their help in conducting the experiments over Deodar leaves.

\section{References}

[1] Capa t R, Khezami L. and Burnham A.K. (2004). Assessment of various kinetic models for the pyrolysis of microgranular cellulose, Thermochim. Acta, 417(1): 79-89.

https://doi.org/10.1016/j.tca.2004.01.029

[2] Con sa J.A., Caballero J.A., Marcilla A. and Font R.(1995). Analysis of different kinetic models in the dynamic pyrolysis of cellulose, Thermochim. Acta, 254: 175-192. https://doi.org/10.1016/0040-6031(94)02102-t

[3] Conesa .A., Marcilla A., Caballero J.A. and Font R. (2001). Comments on the validity and utility of the different methods for kinetic analysis of thermogravimetric data. J. Anal. Appl. Pyrolysis, 617: 58-59. https://doi.org/10.1016/s0165-2370(00)00130-3

[4] ysiak J.J. and Badwi Y. Al. Al. (2004). Kinetic equations for thermal dissociation processes, J. Therm. Anal. Cal., 76: 521-528. https://doi.org/10.1023/b:jtan.0000028030.49773.ad

[5] M syk R.D., Whyman G.E., Savoskin M.V. and Yaroshenko A.P. (2005). Theoretical model and experimental study of pore growth during thermal expansion of graphite intercalation compounds. J. Therm. Anal and Cal. 2005; $79(3)$ : 515-519. https://doi.org/10.1007/s10973-005-0571-3

[6] Criado .M. and Pérez-Maqueda L.A. (2005). Sample controlled thermal analysis and kinetics. J. Therm. Anal. Cal., 80: 27-33.

https://doi.org/10.1007/s10973-005-0609-6 
[7] Burnham A.K. and Braun R.L. (1999). Global kinetic analysis of complex materials. Energy Fuels, 13: 1-22.

https://doi.org/10.1021/ef9800765

[8] Burnham A.K., Schmidt B.J. and Braun R.L. (1995). A test of parallel reaction model using kinetic measurements on hydrous pyrolysis residues. Geochem. 23: 931-939.

https://doi.org/10.1016/0146-6380(95)00069-0

[9] Galgano A. and Blasi C.D. (2003). Modeling wood degradation by the unreacted-core-shrinking approximation. Ind. Eng. Chem. Res, 42: 2101-2111.

https://doi.org/10.1021/ie020939o

[10] Ferdous D, Dalai A.K., Bej S.K. and Thring R.W. (2002). Pyrolysis of lignins: experimental and kinetics studies, Energy Fuels, 16: 14051412.

https://doi.org/10.1021/ef0200323

[11] Brown M.E. (1988). Introduction to Thermal Analysis Techniques and Applications, Chapman and Hall, New York.

https://doi.org/10.1007/978-94-009-1219-9_9

[12] Teng H., Hsieh C.T. (1999).Influence of surface characteristics on liquid-phase adsorption of phenol by activated carbons prepared from bituminous coal. Ind. Engg. Chem. Res, 37: 3618-3624.

https://doi.org/10.1021/ie970796j

[13] Lakshmanan C.C. and White N. (1994). A new distributed activation energy model using Weibull distribution for the representation of complex kinetics. Energy Fuels, 8: 1158-1167.

https://doi.org/10.1021/ef00048a001

[14] Giuntoli J., de Jong W., Arvelakis S., Spliethoff H., Verkooijen A.H.M. (2009).Quantitative and kinetic TG-FTIR study of biomass residue pyrolysis: Dry distiller's grains with solubles (DDGS) and chicken manure Journal of Analytical and Applied Pyrolysis, 85(1): 301-312.

https://doi.org/10.1016/j.jaap.2008.12.007

[15] Lapuerta M., Hernández J.J., Rodríguez J. (2004). Kinetics of devolatilisation of forestry wastes from thermogravimetric analysis, Biomass and Bioenergy, 27(4): 385-91.

https://doi.org/10.1016/j.biombioe.2003.11.010

[16] Zhu H.M., Yan J.H., Jiang X.G., Lai Y.E., Cen K.F. (2009). Analysis Of Volatile Species Kinetics During Typical Medical Waste Materials Pyrolysis Using A Distributed Activation Energy Model", Journal Of Hazardous Materials, 162(2): 646-651.

https://doi.org/10.1016/j.jhazmat.2008.05.077 
[17] Koreňová Z., Juma M., Annus J., Markoš J. and Jelemensky L. (2006). Kinetics of pyrolysis and properties of carbon black from a scrap tire. Chemical Papers, 60: 422-426.

https://doi.org/10.2478/s11696-006-0077-x

[18] Quan C., Li A. and Gao N. (2009). Thermogravimetric analysis and kinetic study on large particles of printed circuit board wastes. Waste Management, 29: 2353-2360.

https://doi.org/10.1016/j.wasman.2009.03.020

[19] Folgueras M.B., Díaz R.M., Xiberta J. and Prieto I. (2003). Thermogravimetric analysis of the co-combustion of coal and sewage sludge, Fuel, 82, pp. 1051-1055.

https://doi.org/10.1016/s0016-2361(03)00161-3

[20] Otero M., Calvo L.F., Gil M.V., García A.I. and Morán A. (2008). Cocombustion of Different Sewage Sludge And Coal: A non isothermal thermogravimetric kinetic analysis, Bioresource Technology, 99: 6311-19.

https://doi.org/10.1016/j.biortech.2007.12.011

[21] Howard J.B., in Chemistry of Coal Utilization, (M.A.Elliott, Ed) Wiley \& Sons (1981) Ch. 12.

[22] Suuberg E.M. (1983). Approximate solution technique for nonisothermal, Gaussian distributed activation energy models, Combust. Flame 50: 243.

https://doi.org/10.1016/0010-2180 (83)90066-4

[23] Skrdla P.J. and Roberson R.T. (2005). Semiempirical equations for modeling solid-state kinetics based on a Maxwell-Boltzmann distribution of activation energies: applications to a polymorphic transformation under crystallization slurry conditions and to the thermal decomposition of AgMnO4 crystals. J. Phys. Chem. B, 109: 10611-10619.

https://doi.org/10.1021/jp045268h

[24] Dhaundiyal A. and Tewari P.C. (2017). Kinetic Parameters for the Thermal Decomposition of Forest Waste Using Distributed Activation Energy Model (DAEM), Environmental and Climate Technologies, 19(1): 15-32.

https://doi.org/10.1515/rtuect-2017-0002

[25] Dhaundiyal A. and Singh S.B. (2017). Mathematical insight to non-isothermal pyrolysis of pine needles for different probability distribution functions, Biofuels, 1-12.

http://dx.doi.org/10.1080/17597269.2017.1329495

[26] Vand V., Proc. Phys. Soc. (London). (1943). A theory of the irreversible electrical resistance changes of metallic films evaporated in vacuum. A55: 222.

https://doi.org/10.1088/0959-5309/55/3/308 
[27] Pitt G.J. (1962). The kinetics of the evolution of volatile products from coal. Fuel 1:267 (1962).

[28] Speight J.G. (1994). The Chemistry and Technology of Coal, Second Edition, CRC press.

[29] Dhaundiyal A. and Singh S.B. (2017). Parametric Study of nth Order Distributed Activation Energy Model for Isothermal Pyrolysis of Forest Waste Using Gaussian Distribution. Acta Technologica Agriculturae, 20(1): 23-28.

https://doi.org/10.1515/ata-2017-0005

[30] Dhaundiyal A. and Singh S.B. (2016). Asymptotic approximations to the distributed activation energy model for non isothermal pyrolysis of loose biomass using the Weibull distribution, Archivum Combustionis, 36(2): 131-146

[31] Dhaundiyal A. and Singh S.B. (2016). Asymptotic solution to the isothermal nth order distributed activation energy model using the Rayleigh Distribution, Journal of Natural Resources and Development, 6: $92-98$.

\section{Aproximaciones asintóticas a la pirólisis isotérmica de hojas de deodara usando la distribución gamma}

Resumen. El propósito principal de este artículo gira en torno de la influencia que tienen ciertos parámetros relacionados con la pirólisis de biomasa sobre las soluciones numéricas del modelo de energía de activación distribuida (MEAD) de orden $n$, usando la distribución Gamma. Se estudian el límite superior de la integral 'dE', el factor de frecuencia, el orden de reacción, y los parámetros de forma y velocidad de la distribución Gamma. El análisis del modelo matemático es realizado con ayuda de una expansión asintótica.

Palabras clave: expansión asintótica; distribución Gamma; pirólisis de biomasa; modelo de energía de activación distribuida

\section{Aproximações assintóticas à pirólise isotérmica de folhas de deodara com a distribuição gamma}

Resumo. O objetivo principal deste artigo gira em torno da influência de certos parâmetros relacionados à pirólise de biomassa nas soluções numéricas do modelo de energia de ativação distribuída (MEAD) de ordem $n$, usando a distribuição Gamma. São estudados o limite superior da integral 'dE', o fator de frequência, a ordem da reação, e os parâmetros de forma e velocidade da distribuição Gamma. A análise do modelo matemático é realizada com a ajuda de uma expansão assintótica.

Palavras-chave: expansão assintótica; distribuição gama; pirólise de biomassa; modelo de energia de ativação distribuída 


\section{Mr. Alok Dhaundiyal}

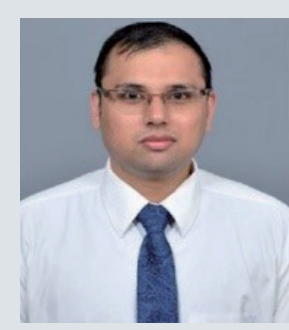

Was a Professor (Assistant) in the Department of Mechanical Engineering, Himgiri Zee University, Dehradun, U.K., India. He has also worked on Deutsche Gesellschaft für Internationale Zusammenarbeit (GIZ) projects, which are the part of Indo-German Govt. Programme to promote renewable energy sector of India under the patronage of state government agency of Uttrakhand, India, UREDA; and Central ministry, Ministry of New Renewable Energy. His area of interest is the energy generation through the biomass waste utilization. In 2017, He received the Stipendium Hungaricum award granted by the government of Hungary. The Faculty of Engineering Excellence award has been conferred on him by the University of Strathclyde and United Kingdom. He has also received University Grant Commission (2017 to 2022) and GATE (2012 to 2014) scholarships for his higher studies. Currently, he is a PhD (Mechanical) student in Szent Istvan University, Hungary.

Dr. S. B. Singh

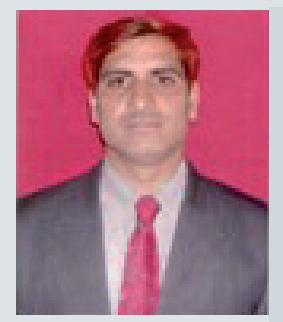

Is a Professor in the Department of Mathematics, Statistics and Computer Science, G. B. Pant University of Agriculture and Technology, Pantnagar, India. He has 24 years of teaching and research experience with Undergraduate and Post Graduate students at different Engineering Colleges and University. Prof. Singh is a member of Indian Mathematical Society, Operations Research Society of India, ISST, and National Society for Prevention of Blindness in India and Member of Indian Science Congress Association. He is a regular reviewer of many books and International/National Journals. Mr. Singh has been a member of organizing committees in many international and national conferences and workshops. He is an Editor of the Journal of Reliability and Statistical Studies. He has authored and co-authored eight books on different courses of Applied/ Engineering Mathematics. He has won five national awards. He has published his research works at national and international journals of repute. His area of research is Reliability Theory. 